Nevşehir Bilim ve Teknoloji Dergisi TARGíD Özel Sayı 62-68 2016

DOI: 10.17100/nevbiltek.210964

URL: http://dx.doi.org/10.17100/nevbiltek.210964

\title{
Bazı Yem Bezelyesi Hat ve Çeşitlerinin Farkı Sıcaklıklarda Çimlenme ve Çıkış Performanslarının Belirlenmesi
}

\author{
Erdal Çaçan ${ }^{1, *}$, Nusret Özbay², Kağan Kökten ${ }^{3}$ \\ ${ }^{1}$ Bingöl Üniversitesi Genç Meslek Yüksekokulu, Bitkisel ve Hayvansal Üretim Bölümü, Bingöl, Türkiye. \\ ${ }^{2}$ Bingöl Üniversitesi Ziraat Fakültesi, Bahçe Bitkileri Bölümü, Bingöl, Türkiye. \\ ${ }^{3}$ Bingöl Üniversitesi Ziraat Fakültesi, Tarla Bitkileri Bölümü, Bingöl, Türkiye. \\ Öz
}

$\mathrm{Bu}$ çalışma, bazı yem bezelyesi (Pisum sativum ssp. arvense L.) hat ve çeşitlerinin farklı sıcaklıklarda çimlenme ve çıkış oranlarının belirlenmesi amacıyla yürütülmüştür. Denemede materyal olarak 13 adet yem bezelyesi hat ve çeşidi kullanılmıştır. Yem bezelyesi tohumları dört farklı sıcaklıkta $\left(10^{\circ} \mathrm{C}, 20^{\circ} \mathrm{C}, 24^{\circ} \mathrm{C}\right.$ ve $\left.30^{\circ} \mathrm{C}\right)$ çimlenme ve çıkış testlerine tabi tutulmuştur. Hat ve çeşitler çimlenme oranı ve hızı ile çıkış oranı ve hızı bakımından karşılaştırılmıştır. Araştırma sonuçlarına göre en iyi çimlenme oranları $10^{\circ} \mathrm{C}, 20^{\circ} \mathrm{C}$ ve $24{ }^{\circ} \mathrm{C}$ 'de çimlendirilen yem bezelyesi tohumlarından elde edilmiştir. Bu sıcaklıklarda en yüksek çimlenme oranı istatistiksel olarak aynı grupta yer alan 88P038-4-3-683, Spring pea 3-638, P57B, P101 ve P104 hatları ile Atos ve Özkaynak çeşitlerinden elde edilmiştir. Tüm sıcaklık değerlerinde benzer çıkış oranları elde edilmesine karşın 88P038-4-3-683, Spring pea 3-638, P57B ve P101 hatları ile Özkaynak, Reyna ve Bolero çeşitlerinin en yüksek değerleri vererek öne çıktıkları tespit edilmiştir. Hem çimlenme oranı hem de çıkış oranı açısından en iyi performans Spring pea 3-638, P101 ve P104 hatlarından elde edilmiştir. Sıcaklık arttıkça çimlenme ve çıkış hızları da doğru orantılı bir şekilde artmıştır.

Anahtar Kelimeler: Yem bezelyesi, Çimlenme, Çıkış, Sıcaklık

\section{Determination of Germination and Emergence Performances of Some Forage Pea Lines and Varieties at Different Temperatures}

Abstract

This study was conducted to determine germination and emergence rates of some forage pea (Pisum sativum ssp. arvense L.) lines and varieties at different temperatures. As plant material, 13 forage pea lines and varieties were used for the experiment. The forage pea seeds were subjected to germination and emergence tests at four different temperatures $\left(10{ }^{\circ} \mathrm{C}, 20{ }^{\circ} \mathrm{C}, 24{ }^{\circ} \mathrm{C}\right.$, and $\left.30{ }^{\circ} \mathrm{C}\right)$. The lines and varieties were compared for rates and percentages of germination and emergence. According to the research results, the best germination rates were obtained from forage pea seeds germinated at $10{ }^{0} \mathrm{C}, 20{ }^{0} \mathrm{C}$, and $24{ }^{0} \mathrm{C}$. At these temperatures, the highest germination and emergence rates were obtained from 88P038-4-3-683, Spring pea 3-638, P57B, P101, P104, Atos and Özkaynak lines and/or varieties falling into the same group as the statistical. Although similar emergence rates were obtained at all temperatures evaluated, giving the highest values of 88P038-4-3-683, Spring pea 3-638, P57B ve P101, Özkaynak, Reyna and Bolero lines and varieties were found to be come forward. The best performance in terms of both emergence and germination rate was obtained from the Spring pea 3-638, P101, and P104 lines. Germination and emergence rates increased with increasing temperature.

Keywords: Forage pea, Germination, Emergence, Temperature

"e-mail: ecacan@bingol.edu.tr 


\section{Giriş}

İnsanların sağlıklı bir şekilde beslenebilmesi için hayvansal proteinler büyük bir öneme sahiptir. Dengeli beslenmede besinlerin \%40'ının hayvansal, \%60'ının ise bitkisel içerikli gıdalardan karşılanması gerekmektedir. Dünyada kişi başına günlük 70.9 g protein tüketilmekte ve bunun \%65'i bitkisel, \%35’i ise hayvansal gıdalardan temin edilmektedir. Ülkemizde ise günlük tüketilen protein miktarı $85.0 \mathrm{~g}$ olup, bunun \%80'i bitkisel ve \%20'si hayvansal gidalardan oluşmaktadır [1].

Doğu Anadolu Bölgesinin iklimi daha çok serin iklim yem bitkisi türlerinin yetiştirilmesine uygundur. Yem bezelyesi bir serin iklim yem bitkisi türüdür. Bu nedenle yem bezelyesinin bölgemizde yetiştirilme potansiyeli oldukça yüksektir. İklimin sert olması nedeni ile bazı yem bitkilerinin sonbaharda ekilip yetiştirilememesine rağmen bölgemizin kırsal kesimlerinde teşvik edilmesi gerekmektedir. Baklagil yem bitkisi olması sebebi ile bölge tarımında uygulanacak ekim nöbeti planlarına konularak, yetiştirilmesi yaygınlaştırılabilir ve ekilen topraklar azot yönünden de zenginleştirilebilir.

Yem bezelyesi tek y1llık bir baklagil yem bitkisi olup otunun besleme değeri oldukça yüksek ve lezzetlidir. Her türlü hayvan için lezzetli ve besleyici bir ota sahiptir. Kuru ot amaciyla tam çiçeklenme döneminde biçilen yem bezelyesi, \%20 civarında ham protein içermektedir. Ayrıca, yem bezelyesinin taneleri de çok değerli bir kesif yemdir. Taneler \%20-30 arasında ham protein, özellikle lisin içermektedir. Taneleri kırılarak diğer kaba yemlerle birlikte yem rasyonlarına konulmaktadır. Batı Avrupa ülkelerinde rasyonlarda soyanın yerine yem bezelyesi taneleri kullanılmaktadır [2]. Hem yeşil ve kuru otundan hem de tanelerinden yem bitkisi olarak yararlandığımız yem bezelyesi aynı zamanda mera bitkisi ve yeşil gübre olarak da kullanılmaktadır [3 ve 4]. Bu çalışma; bazı yem bezelyesi hat ve çeşitlerinin farklı sıcaklıklardaki çimlenme ve çıkış oranlarının tespit edilmesi amacıyla yürütülmüştür.

\section{Materyal ve Metot}

Bu çalışma 2014 yılının Kasım ayında Bingöl Üniversitesi Ziraat Fakültesi Bahçe Bitkileri laboratuvarında yürütülmüştür. Materyal olarak; 88P038-4-3-683, Spring pea 3-638, P57B, P51, P101, P104 ve P57K hatları ile Atos, Özkaynak, Reyna, Ultrillo, Spring ve Bolero çeşitleri olmak üzere toplam 13 adet yem bezelyesi kullanılmıştır. Yem bezelyesi hat ve çeşitleri GAP Uluslararası Tarımsal Araştırma ve Eğitim Merkezi'nden temin edilmiştir.

Çimlenme oranlarını belirlemek amacıyla yem bezelyesi hat ve çeşitlerine ait tohumlar temizlenip iyice karıştırıldıktan sonra içinden 3 tekerrürlü olacak şekilde toplam 60 adet tohum (her tekerrür için 20 adet tohum) sayılmıştır. Sayılan tohumlar daha sonra içerisinde iki kat filtre kâğıdı olan petri kaplarına yerleştirilmiştir. Çıkış oranlarını belirlemek amacıyla da aynı şekilde hazırlanan 60 adet tohum (her tekerrür için 20 adet tohum) içerisinde 3:1 oranında torf ve perlit olan plastik kaplara (çap 7 $\mathrm{cm}$, derinlik $3.5 \mathrm{~cm}$ ) yerleştirilmiştir.

Petri kapları ve çıkış testi için kullanılan plastik kaplar distile su ile sulanıp, sıcaklıkları $10{ }^{\circ} \mathrm{C}$, $20{ }^{\circ} \mathrm{C}, 24{ }^{\circ} \mathrm{C}$ ve $30{ }^{\circ} \mathrm{C}$ olacak şekilde ayarlanan inkübatörlere yerleştirilmiştir. Çimlenme ve çıkış testleri karanlık ortamda gerçekleştirilmiştir. Çimlendirme ve çıkış ortamının ihtiyacına göre zaman zaman su ilavesi yapılmıştır. Deneme süresince boyunca her gün çimlenen tohumlar sayılarak not edilmiş ve petrilerden uzaklaştırılmıştır. Çimlenmeye esas olarak kökçük ucunun çıplak gözle görülebilmesi veya kökçügün $2 \mathrm{~mm}$ büyüklüğünde olması yeterli kabul edilmiştir. 
Günlük olarak hipokotili torf yüzeyinde görünen fideler de çıkış yapanlar olarak kabul edilmiştir. Tohum kaplarından üç gün boyunca çimlenme ve çıkış yapmayanlar sonlandırılmak koşuluyla deneme 20 gün devam etmiştir. Çimlenme ve çıkış yapan tohum sayıları 100 ile çarpılıp, 20'ye bölünerek çimlenme ve çıkış oranları yüzde olarak belirlenmiş̧ir. Çimlenme ve çıkış oranlarına ait çimlenme hızları aşağıdaki formül [5] yardımıyla belirlenmiştir.

$\Sigma$ n (Sayımın yapıldığı gün çimlenen tohum s.) x d (Sayımın yapıldığı gün)

Çimlenme Hızı =

$\Sigma$ n (Toplam çimlenmiş tohum sayısı)

Araştırma sonucunda elde edilen veriler, tesadüf parselleri deneme deseninde faktöriyel düzene göre 3 tekerrürlü olarak JUMP istatistiki paket programıyla analiz edilmiştir. Varyans analizi sonuçlarına göre istatistiksel olarak önemli çıkan faktör ortalamaları LSD testi ile karşılaştırılmıştır.

\section{Bulgular}

\section{1. Çimlenme Oranı (\%)}

Araştırmada kullanılan yem bezelyesi hat ve çeşitlerine ait çimlenme oranları Tablo 1'de verilmiştir. Tablo 1'de görüldüğü gibi, çimlenme oranları açısından hat ve çeşitler arasında istatistiki olarak farklılıkların olduğu görülmektedir.

En fazla çimlenme oranının \%91.0 ile $24{ }^{\circ} \mathrm{C}$ sıcaklıkta ve \%88.7 oranı ile $10{ }^{0} \mathrm{C}$ ve $20{ }^{\circ} \mathrm{C}$ sıcaklıklarda gerçekleştiği ve bu sıcaklıktaki çimlenme oranlarının istatistiksel olarak aynı grupta yer aldıkları görülmektedir. Çimlenme oran $30{ }^{\circ} \mathrm{C}$ sıcaklıkta ise \%78.6 olarak belirlenmiş ve istatistiksel olarak en düşük çimlenme oranı bu sıcaklıkta tespit edilmiştir. En düşük çimlenme oranı $30{ }^{\circ} \mathrm{C}$ elde edilmesine rağmen P57K hattının bu sıcaklıkta \%100 çimlenme oranı göstererek ön plana çıktığı görülmektedir. Çalışılan tüm yem bezelyelerinin ortalamalarına bakıldığında; en yüksek çimlenme oranı Spring pea 3-638, P101, P104, P57B, 88P038-4-3-683 ve P51 hatları ile Atos, Spring ve Özkaynak çeşitlerinden elde edilmiştir. Yem bezelyesinin çimlenebilmesi için toprak sıcaklığının asgari $4-6{ }^{0} \mathrm{C}$, optimum çimlenme için ise $16-18{ }^{\circ} \mathrm{C}$ olması gerekmektedir [6].

Tablo 1. Bazı Yem Bezelyesi Çeşitlerinin Farklı Sıcaklıklarda Çimlenme Oranları (\%)

\begin{tabular}{ccccccccccc}
\hline Çeşitler & \multicolumn{2}{c}{$\mathbf{1 0}{ }^{\mathbf{0}} \mathbf{C}$} & \multicolumn{2}{c}{$\mathbf{2 4}^{\mathbf{0}} \mathbf{C}$} & \multicolumn{2}{c}{$\mathbf{3 0}^{\mathbf{}} \mathbf{C}$} & \multicolumn{2}{c}{ Ortalama } \\
\hline 88P038-4-3-683 & 85,0 & a & 95,0 & ab & 90,0 & ab & 80,0 & b & 87,5 & A-C \\
Atos & 95,0 & a & 90,0 & a-c & 91,7 & ab & 88,3 & ab & 91,3 & AB \\
Bolero & 95,0 & a & 85,0 & bc & 90,0 & ab & 58,3 & cd & 82,1 & B-E \\
Özkaynak & 93,3 & a & 90,0 & a-c & 95,0 & a & 81,7 & b & 90,0 & A-C \\
P101 & 93,3 & a & 98,3 & a & 91,7 & ab & 85,0 & ab & 92,1 & A \\
P104 & 95,0 & a & 96,7 & a & 91,7 & ab & 85,0 & ab & 92,1 & A \\
P51 & 91,7 & a & 83,3 & cd & 95,0 & a & 78,3 & b & 87,1 & A-D \\
P57B & 95,0 & a & 95,0 & ab & 95,0 & a & 83,3 & ab & 92,1 & A \\
P57K & 46,7 & b & 73,3 & d & 91,7 & ab & 100,0 & a & 77,9 & DE \\
Reyna & 88,3 & a & 81,7 & cd & 80,0 & b & 46,7 & d & 74,2 & E \\
Spring & 96,7 & a & 85,0 & bc & 90,0 & ab & 73,3 & bc & 86,3 & A-D \\
Spring pea 3-638 & 95,0 & a & 100,0 & a & 93,3 & ab & 88,3 & ab & 94,2 & A \\
Ultrillo & 83,3 & a & 80,0 & cd & 88,3 & ab & 73,3 & bc & 81,3 & C-E \\
Ortalama & 88,7 & A & 88,7 & A & 91,0 & A & 78,6 & B & 86,8 & \\
\hline
\end{tabular}




\section{2. Çimlenme Hızı (Gün)}

Araştırmada kullanılan yem bezelyesi hat ve çeşitlerine ait çimlenme hızları Tablo 2'de verilmiştir. Tablo 2'de görüldüğü gibi, çimlenme hızları açısından hat ve çeşitler arasında istatistiki olarak farklılıkların olduğu görülmektedir.

Çalışılan hat ve çeşitlerin çimlenme hızı $10{ }^{\circ} \mathrm{C}$ 'de 5.37 gün olarak tespit edilmiştir. Bu değer 20 ${ }^{0} \mathrm{C}$ sıcaklıkta 2.89 gün, $24{ }^{0} \mathrm{C}$ sıcaklıkta 3.06 gün ve $30{ }^{\circ} \mathrm{C}$ sicaklıkta ise 3.09 gün olarak tespit edilen hızlardan daha düşük ve istatistiksel olarak farklı bulunmuştur. Çalışılan tüm yem bezelyelerinin ortalamalarına bakıldığında; en yüksek çimlenme hızı Özkaynak çeşidi ile 88P038-4-3-683, P104 ve P57B hatlarından elde edilmiştir. Çimlenme oranı ve çimlenme hızı ile ilgili elde ettiğimiz bulgular literatür bulguları ile uyum içerisindedir [7-11].

Tablo 2. Bazı Yem Bezelyesi Çeşitlerinin Farklı Sıcaklıklarda Çimlenme Hızları (Gün)

\begin{tabular}{|c|c|c|c|c|c|c|c|c|c|c|}
\hline \multirow{2}{*}{$\begin{array}{c}\text { Çeşitler } \\
\text { 88P038-4-3-683 }\end{array}$} & \multicolumn{2}{|c|}{$10^{0} \mathrm{C}$} & \multicolumn{2}{|c|}{$20^{0} \mathrm{C}$} & \multicolumn{2}{|c|}{$24{ }^{0} \mathrm{C}$} & \multicolumn{2}{|c|}{$30^{0} \mathrm{C}$} & \multicolumn{2}{|c|}{ Ortalama } \\
\hline & 5,01 & de & 2,31 & e & 2,66 & c-e & 2,74 & de & 3,18 & $\mathrm{D}-\mathrm{F}$ \\
\hline Atos & 5,19 & de & 3,28 & a & 3,24 & bc & 3,37 & b-d & 3,77 & $\mathrm{AB}$ \\
\hline Bolero & 6,98 & $\mathrm{a}$ & 3,18 & $\mathrm{ab}$ & 3,06 & cd & 3,00 & b-d & 4,05 & A \\
\hline Özkaynak & 3,77 & $\mathrm{f}$ & 3,00 & $a-d$ & 2,35 & e & 2,22 & e & 2,84 & $\mathrm{~F}$ \\
\hline P101 & 5,59 & $\mathrm{~cd}$ & 2,73 & a-e & 3,11 & c & 2,81 & c-e & 3,56 & B-D \\
\hline P104 & 4,72 & $\mathrm{e}$ & 2,62 & b-e & 2,51 & de & 2,75 & c-e & 3,15 & $\mathrm{D}-\mathrm{F}$ \\
\hline P51 & 5,03 & de & 3,03 & $\mathrm{a}-\mathrm{d}$ & 2,98 & cd & 3,42 & bc & 3,61 & BC \\
\hline P57B & 4,74 & e & 2,58 & c-e & 2,33 & e & 2,73 & de & 3,09 & $\mathrm{EF}$ \\
\hline P57K & 4,82 & e & 3,06 & $\mathrm{a}-\mathrm{c}$ & 4,51 & a & 4,27 & a & 4,16 & A \\
\hline Reyna & 6,48 & $\mathrm{ab}$ & 3,26 & a & 3,79 & $\mathrm{~b}$ & 3,14 & b-d & 4,17 & A \\
\hline Spring & 5,96 & bc & 3,04 & $\mathrm{a}-\mathrm{d}$ & 3,22 & bc & 3,57 & $\mathrm{~b}$ & 3,95 & $\mathrm{AB}$ \\
\hline Spring pea 3-638 & 5,00 & de & 2,48 & de & 2,82 & c-e & 2,88 & c-e & 3,30 & C-E \\
\hline Ultrillo & 6,48 & $a b$ & 2,96 & $\mathrm{a}-\mathrm{d}$ & 3,13 & C & 3,33 & b-d & 3,97 & $\mathrm{AB}$ \\
\hline Ortalama & 5,37 & $\mathrm{~A}$ & 2,89 & $\mathrm{~B}$ & 3,06 & $\mathrm{~B}$ & 3,09 & $\mathrm{~B}$ & 3,60 & \\
\hline
\end{tabular}

\section{3. Çıkış Oranı (\%)}

Araştırmada kullanılan yem bezelyesi hat ve çeşitlerine ait çıkış oranları Tablo 3’te verilmiştir.

Tablo 3’te görüldüğü gibi, çimlenme oranları açısından hat ve çeşitler arasında istatistiki olarak farklılıkların olduğu görülmektedir.

Tablo 3. Bazı Yem Bezelyesi Çeşitlerinin Farklı Sıcaklıklarda Çıkış Oranları (\%)

\begin{tabular}{|c|c|c|c|c|c|c|c|c|c|c|}
\hline \multirow{2}{*}{$\begin{array}{c}\text { Çeşitler } \\
\text { 88P038-4-3-683 }\end{array}$} & \multicolumn{2}{|c|}{$10^{0} \mathrm{C}$} & \multicolumn{2}{|c|}{$20^{0} \mathrm{C}$} & \multicolumn{2}{|c|}{$24^{0} \mathrm{C}$} & \multicolumn{2}{|c|}{$30^{0} \mathrm{C}$} & \multicolumn{2}{|c|}{ Ortalama } \\
\hline & 88,3 & $\mathrm{a}$ & 78,3 & $\mathrm{a}-\mathrm{c}$ & 70,0 & $\mathrm{ab}$ & 65,0 & $\mathrm{a}$ & 75,4 & A-C \\
\hline Atos & 81,7 & $\mathrm{ab}$ & 58,3 & C & 68,3 & $\mathrm{ab}$ & 75,0 & $\mathrm{a}$ & 70,8 & A-C \\
\hline Bolero & 86,7 & $\mathrm{ab}$ & 80,0 & $a-c$ & 85,0 & $\mathrm{a}$ & 70,0 & $\mathrm{a}$ & 80,4 & $\mathrm{AB}$ \\
\hline Özkaynak & 90,0 & a & 88,3 & $\mathrm{a}$ & 85,0 & $\mathrm{a}$ & 76,7 & $\mathrm{a}$ & 85,0 & A \\
\hline P101 & 81,7 & $\mathrm{ab}$ & 90,0 & $\mathrm{a}$ & 68,3 & $a b$ & 86,7 & $\mathrm{a}$ & 81,7 & $\mathrm{AB}$ \\
\hline P104 & 65,0 & b-d & 63,3 & bc & 81,7 & $a b$ & 85,0 & $\mathrm{a}$ & 73,8 & A-C \\
\hline P51 & 81,7 & $\mathrm{ab}$ & 81,7 & $a-c$ & 58,3 & $\mathrm{ab}$ & 30,0 & b & 62,9 & $\mathrm{C}$ \\
\hline P57B & 78,3 & $\mathrm{ab}$ & 68,3 & $a-c$ & 63,3 & $\mathrm{ab}$ & 91,7 & $\mathrm{a}$ & 75,4 & A-C \\
\hline P57K & 45,0 & de & 91,7 & $\mathrm{a}$ & 53,3 & b & 76,7 & $\mathrm{a}$ & 66,7 & $\mathrm{BC}$ \\
\hline Reyna & 71,7 & $a-c$ & 86,7 & $a b$ & 68,3 & $\mathrm{ab}$ & 90,0 & $\mathrm{a}$ & 79,2 & $\mathrm{AB}$ \\
\hline
\end{tabular}


Çaçan E., Özbay N., Kökten K.

\begin{tabular}{ccccccccccc} 
Spring & 33,3 & e & 85,0 & ab & 83,3 & ab & 68,3 & a & 67,5 & BC \\
Spring pea 3-638 & 88,3 & a & 73,3 & a-c & 85,0 & a & 93,3 & a & 85,0 & A \\
Ultrillo & 51,7 & c-e & 75,0 & a-c & 55,0 & ab & 73,3 & a & 63,8 & C \\
\hline Ortalama & 72,6 & & 78,5 & & 71,2 & & 75,5 & & 74,4 & \\
\hline
\end{tabular}

Çalışılan hat ve çeşitlerin çimlenme oranı ortalama olarak; $10{ }^{0} \mathrm{C}$ sıcaklıkta $\% 72.6,20{ }^{0} \mathrm{C}$ sıcaklıkta \%78.5, $24{ }^{0} \mathrm{C}$ sıcaklıkta $\% 71.2$ ve $30{ }^{0} \mathrm{C}$ sıcaklıkta ise $\% 75.5$ olarak tespit edilmiştir. Tespit edilen bu değerler arasında istatistiksel olarak bir farklılık görülmemiştir. Çalışılan tüm yem bezelyelerinin ortalamalarına bakıldığında; en yüksek çıkış oranı P51 ve P57K hatları ile Spring ve Utrillo çeşitleri haricindeki diğer tüm çeşit ve hatlardan elde edilmiştir. 2004 yılında yapılan bir çalışmada, Pisum sativum için optimum çimlenme ve çıkış sıcaklığının $20{ }^{0} \mathrm{C}$ olduğu bildirilmektedir [12]. Yüksek toprak sıcaklığı çıkışların kötü olmasına neden olmaktadır [6].

\section{4. Çıkış Hızı (Gün)}

Araştırmada kullanılan yem bezelyesi hat ve çeşitlerine ait çıkış hızları Tablo 4'te verilmiştir. Tablo 4'te görüldüğü gibi, çıkış hızları açısından hat ve çeşitler arasında istatistiki olarak farklı1ıkların olduğu görülmektedir.

Çalışılan hat ve çeşitlerin çıkış hızı ortalama olarak; $10{ }^{\circ} \mathrm{C}$ sıcaklıkta 11.95 gün, $20{ }^{\circ} \mathrm{C}$ sıcaklıkta 3.60 gün, $24{ }^{\circ} \mathrm{C}$ sıcaklıkta 3.28 gün ve $30{ }^{\circ} \mathrm{C}$ sıcaklıkta ise 3.19 gün olarak hesaplanmıştır. $10{ }^{0} \mathrm{C}$ sıcaklıkta elde edilen çıkış hızı oranı (11.95 gün) diğer ortalama oranlarından daha düşük ve istatistiksel olarak farklı bulunmuştur. Çalışılan tüm yem bezelyelerinin ortalamalarına bakıldığında; en yüksek çıkış hızı P104, P51 ve P57K hatları ile Spring çeşidi dışındaki diğer tüm çeşit ve hatlardan elde edilmiştir. Sıcaklık arttıkça çıkış hızının da sıcaklıkla doğru orantılı bir şekilde arttığı görülmektedir. Çıkış oranı ve çıkış hızı ile ilgili elde ettiğimiz literatür bulguları ile uyum içerisindedir [7-11].

Tablo 4. Bazı Yem Bezelyesi Çeşitlerinin Farklı Sıcaklıklarda Çıkış Hızları (Gün)

\begin{tabular}{|c|c|c|c|c|c|c|c|c|c|c|}
\hline \multirow{2}{*}{$\begin{array}{c}\text { Çeşitler } \\
\text { 88P038-4-3-683 }\end{array}$} & \multicolumn{2}{|c|}{$10^{0} \mathrm{C}$} & \multicolumn{2}{|c|}{$20^{0} \mathrm{C}$} & \multicolumn{2}{|c|}{$24^{0} \mathrm{C}$} & \multicolumn{2}{|c|}{$30^{\circ} \mathrm{C}$} & \multicolumn{2}{|c|}{ Ortalama } \\
\hline & 11,05 & c-e & 3,33 & b-d & 3,30 & bc & 2,89 & C & 5,14 & $\mathrm{BC}$ \\
\hline Atos & 11,51 & b-e & 2,91 & d & 2,90 & c & 2,68 & c & 5,00 & $\mathrm{C}$ \\
\hline Bolero & 11,31 & b-e & 3,13 & d & 3,01 & c & 3,20 & bc & 5,16 & $\mathrm{BC}$ \\
\hline Özkaynak & 10,30 & e & 3,22 & $\mathrm{~cd}$ & 4,02 & $\mathrm{~b}$ & 2,78 & c & 5,08 & $\mathrm{BC}$ \\
\hline P101 & 12,12 & b-e & 3,44 & b-d & 3,17 & bc & 2,59 & c & 5,33 & $\mathrm{BC}$ \\
\hline P104 & 13,02 & $\mathrm{ab}$ & 4,07 & b & 2,79 & C & 3,36 & bc & 5,81 & $\mathrm{AB}$ \\
\hline P51 & 12,30 & b-d & 5,15 & $\mathrm{a}$ & 3,02 & $\mathrm{C}$ & 2,58 & $\mathrm{C}$ & 5,76 & $A-C$ \\
\hline P57B & 10,23 & e & 3,26 & $\mathrm{~cd}$ & 3,20 & bc & 3,87 & $\mathrm{ab}$ & 5,14 & $\mathrm{BC}$ \\
\hline P57K & 10,87 & de & 5,25 & $\mathrm{a}$ & 5,16 & $\mathrm{a}$ & 4,39 & $\mathrm{a}$ & 6,42 & A \\
\hline Reyna & 12,80 & $b-d$ & 2,96 & d & 3,46 & bc & 2,91 & C & 5,53 & $\mathrm{BC}$ \\
\hline Spring & 14,85 & $\mathrm{a}$ & 3,97 & bc & 3,06 & $\mathrm{C}$ & 3,85 & $\mathrm{ab}$ & 6,43 & A \\
\hline Spring pea 3-638 & 12,05 & b-e & 3,34 & b-d & 2,78 & $\mathrm{C}$ & 3,21 & bc & 5,35 & $\mathrm{BC}$ \\
\hline Ultrillo & 12,97 & $\mathrm{a}-\mathrm{c}$ & 2,79 & d & 2,75 & C & 3,23 & bc & 5,43 & $\mathrm{BC}$ \\
\hline Ortalama & 11,95 & $\mathrm{~A}$ & 3,60 & B & 3,28 & B & 3,19 & $\mathrm{~B}$ & 5,51 & \\
\hline
\end{tabular}




\section{Tartışma ve Sonuç}

Çalışılan yem bezelyesi çeşitlerini çimlenme oranı açısından değerlendirdiğimizde, $10{ }^{0} \mathrm{C}, 20{ }^{0} \mathrm{C}$ ve $24{ }^{0} \mathrm{C}$ sıcaklıklardan en iyi çimlenme oranlarının elde edildiği görülmektedir. $10{ }^{0} \mathrm{C}, 20{ }^{0} \mathrm{C}$ ve $24{ }^{0} \mathrm{C}$ sıcaklıklarda 88P038-4-3-683, Atos, Özkaynak, P101, P104, P57B ve Spring pea 3-638 hat ve çeşitleri istatistiksel olarak aynı grupta yer alarak en yüksek değerleri vermiştir. $30{ }^{0} \mathrm{C}$ sıcaklıkta ise çimlenme oranının düştüğü ve bu sıcaklıkta P57K hattının en yüksek değeri verdiği tespit edilmiştir. Düşük sıcaklıkta $\left(10{ }^{0} \mathrm{C}\right)$ çimlenme hızının düştüğü, diğer sıcaklıklarda ise çimlenme hızının benzer ve istatistiksel olarak aynı grupta yer aldığı görülmektedir.

Çalışılan yem bezelyesi çeşitleri çıkış oranı açısından değerlendirildiğinde çıkış oranının tüm sıcaklıklarda benzer sonuçlar verdiği görülmektedir. Tüm sıcaklık değerlerinde 88P038-4-3-683, Bolero, Özkaynak, P101, P57B, Reyna ve Spring pea 3-638 ve çeşitlerinin istatistiksel olarak aynı grupta yer aldıkları ve en yüksek değerleri vererek önce çıktıkları tespit edilmiştir. Sıcaklık arttıkça çıkış oranı hızının da tıpkı çimlenme oranında olduğu gibi doğru orantılı bir şekilde arttığı tespit edilen sonuçlar arasında yer almaktadir.

\section{Kaynaklar}

[1] Sağsöz S., “Önsöz”, Türkiye 3. Çayır Mer’a ve Yem Bitkileri Kongresi, Erzurum, 1996

[2] Manga I., Acar Z., Ayan I., “Baklagil Yem Bitkileri” Ondokuz Mayı Üniversitesi Ziraat Fakültesi Yayınlarl, 342s., Samsun, 1995

[3] Özkaynak I., "Yem bezelyesi (Pisum arvense L.) yerel çeşitleri üzerinde seleksiyon 1slahı çalışmaları”, Ankara Üniversitesi Ziraat Fakültesi Yem Bitkileri, Çayır ve Mer'a Kürsüsü, Ankara, 1980

[4] Açıkgöz E., "Yem Bitkileri” Uludă̆ Üniversitesi Ziraat Fakültesi Yayınları Yenilenmiş 3. Baskl, Uludağ Üniversitesi Vakfı Yayın No: 182.584 s., Bursa, 2001

[5] Ellis R.H., Roberts E.H., “Towards a rational basis for testing seed quality” In Seed Production, Butterwooths, 605-645s, London, 1980

[6] Khan T.N., Ramzan A., Jillani G., Mehmood T., “Morphological performance of peas (Pisum sativum) genotypes under rainfed conditions of Potowar region”, J. Agric. Res., 51(1): 51-60, 2013

[7] Singh N.T., Dhaliwal G.S., "Effect of soil temperature on seedling emergence in different crops" Plant and Soil, 37: 441-444, 1972

[8] Bierhuizen J.F., Wagenvoort W.A., "Some aspects of seed germination in vegetables. 1. The determination and application of heat sums and minimum temperature for germination”, Scientia Horticulturae, 2(3): 213-219, 1974

[9] Rowland G.G., Gusta L.V., "Effects of soaking, seed moisture content, temperature and seed leakage on germination of faba beans (Vicia faba) and peas (Pisum sativum)”, Can. J. Plant Sci., 57: 401-406, 1977

[10] Brar G.S., Gomez J.F., Mc Michael B.L., Matches A.G., Taylor H.M., “Germination of Twenty Forage Legumes as Influenced by Temperature”, Agronomy Journal, 83(1): 173-175, 1991

[11] Sivritepe H.Ö., “Tohum canlılığının değerlendirilmesi” Alatarım Dergisi, 10(2): 94-105, 2011 
Çaçan E., Özbay N., Kökten K.

[12] Sincik M., Bilgili U., Uzun A., Acikgoz E., "Effect of low temperatures on the germination of different field pea genotypes”, Seed Science and Technology, 32(2): 331-339, 2004 